\title{
Keanekaragaman dan struktur komunitas semut pada perkebunan lada di Lampung
}

\author{
Diversity and community structure of ants in pepper plantation, \\ Lampung Province
}

\author{
Yudiyanto $^{1,2}{ }^{*}$, Ibnul Qayim ${ }^{3}$, Abdul Munif ${ }^{4}$, Dede Setiadi $^{3}$, Akhmad Rizali $^{5}$ \\ ${ }^{1}$ Program Studi Biologi Tumbuhan, Sekolah Pascasarjana, Institut Pertanian Bogor \\ Jalan Agatis, Kampus IPB Dramaga, Bogor 16680 \\ ${ }^{2}$ Sekolah Tinggi Agama Islam Negeri Jurai Siwo, Metro \\ Jalan Ki Hajar Dewantara 15A, Kota Metro, Lampung 34111 \\ ${ }^{3}$ Departemen Biologi, Fakultas MIPA, Institut Pertanian Bogor \\ Jalan Agatis, Kampus IPB Dramaga, Bogor 16680 \\ ${ }^{4}$ Departemen Proteksi Tanaman, Fakultas Pertanian, Institut Pertanian Bogor \\ Jalan Kamper, Kampus IPB Dramaga, Bogor 16680 \\ ${ }^{5}$ Jurusan Hama dan Penyakit Tumbuhan, Fakultas Pertanian, Universitas Brawijaya \\ Jalan Veteran, Malang 65145
}

(diterima Juli 2013, disetujui Mei 2014)

\begin{abstract}
ABSTRAK
Keberadaan semut pada habitat pertanian dipengaruhi oleh ketersediaan makanan dan kesesuaian kondisi lingkungan untuk tempat bersarang. Semut yang umumnya sebagai predator, memiliki peranan yang penting dalam mengendalikan populasi hama di habitat pertanian. Penelitian ini bertujuan untuk memelajari keanekaragaman semut pada perkebunan lada. Hasil yang diperoleh dapat menjadi informasi awal dalam memanfaatkan semut dalam sistem budi daya tanaman lada. Penelitian dilaksanakan pada empat kabupaten di Provinsi Lampung, pada setiap kabupaten dipilih dua plot pengamatan di dalam satu desa. Di setiap plot, semut dikoleksi dengan menggunakan perangkap pitfall. Sebanyak 28 spesies semut dikoleksi dari lahan perkebunan lada di empat kabupaten di Lampung. Dua diantaranya, yaitu Anoplolepis gracilipes dan Solenopsis geminata merupakan spesies semut "tramp" dan bersifat invasif. Terdapat perbedaan komposisi spesies semut antara kabupaten yang berbeda. Keberadaan semut pada perkebunan lada diduga lebih dipengaruhi oleh habitat sekitar dan curah hujan.
\end{abstract}

Kata kunci: perkebunan, Anoplolepis gracilipes, Solenopsis geminata, perangkap pitfall

\begin{abstract}
The occurrence of ants in agricultural habitat is related to the availability of food resources as well as environmental condition for its nesting site. As predator, ants play an important role on controlling pest population in agricultural habitat. The objective of this research was to study the diversity of ants in pepper plantation. The research outcome can be used as basic information for cultivation management of pepper. Ecological observation was conducted in four regencies in Lampung Province with two selected plots on each regency. On each plot, ants were sampled using pitfall traps. In total, 28 ant species were recorded from pepper field in four regencies. Two species i.e. Anoplolepis gracilipes and Solenopsis geminataare well-known as tramp and invasive species. There is significantly different of ant species composition among regencies. The occurrence of ants in pepper plantationis probably affected by habitat condition surrounding pepper plantation and precipitation.
\end{abstract}

Key words: plantation, Anoplolepis gracilipes, Solenopsis geminata, pitfall trap

\footnotetext{
*Penulis korespondensi: Yudiyanto. Sekolah Tinggi Agama Islam Negeri Jurai Siwo, Metro

Jalan Ki Hajar Dewantara 15A, Kota Metro, Lampung 34111

Tel:0725-41507, Faks: 0725-42796, Email: yudiyudi0222@gmail.com
} 


\section{PENDAHULUAN}

Keberadaan serangga pada suatu habitat tidak terlepas dari ketersediaan makanan dan kesesuaian kondisi lingkungan (Schowalter 2011). Pada habitat pertanian seperti persawahan, serangga-serangga herbivora cenderung lebih mendominasi karena ketersediaan tanaman padi sebagai sumber makanan (Settle et al. 1996). Walaupun demikian, serangga-serangga lain baik yang memiliki hubungan tropik dengan serangga herbivor (kelompok predator dan parasitoid) maupun yang tidak memiliki hubungan tropik secara langsung, seperti kelompok pengurai dan polinator, juga ditemukan melimpah pada habitat pertanian (Settle et al. 1996). Keanekaragaman serangga-serangga tersebut bervariasi bergantung pada cara budi daya yang digunakan dan kondisi lahan pertanian (Altieri 1999).

Kawasan pertanian di sekitar habitat alami, seperti hutan cenderung memiliki keanekaragaman serangga yang tinggi dibandingkan dengan lahan pertanian yang monokultur dan dengan sistem budi daya intensif. Lahan persawahan di sekitar hutan alami sebagai contoh, memiliki keanekaragaman serangga termasuk musuh alami yang tinggi sehingga tidak menimbulkan ledakan (outbreak) hama (Rizali et al. 2002). Kondisi habitat dan lingkungan yang mendukung menciptakan keseimbangan dalam hubungan tropik antara tanaman pertanian, serangga herbivor dan musuh alaminya (Tylianakis et al. 2007).

Perubahan yang terjadi pada lahan pertanian, seperti perubahan umur tanaman akan diikuti oleh perubahan keanekaragaman serangga yang ada di dalamnya. Peningkatan umur tanaman akan memengaruhi keberadaan relung (niche) dan ketersediaan makanan. Sebagai contoh, peningkatan umur tanaman perkebunan, seperti kakao memengaruhi peningkatan keanekaragaman semut yang ada pada habitat tersebut (Rizali et al. 2012). Berbeda dengan kakao, pada habitat persawahan menunjukkan bahwa peningkatan umur padi tidak menyebabkan perubahan keanekaragaman semut (Setiani et al. 2010) walaupun untuk kelompok serangga lain menunjukkan perubahan.

Sebagai kelompok serangga terestrial paling dominan, semut mudah dijumpai pada berbagai ekosistem daratan (Wilson 1990). Semut memiliki peranan penting sebagai predator, pengurai dan penyebar biji (Hölldobler \& Wilson 1990). Selain itu, semut juga memiliki sensitivitas yang tinggi terhadap gangguan habitat sehingga semut dapat digunakan sebagai bioindikator perubahan kondisi lahan(Andersenetal.2002). Penelitianinibertujuan untuk mempelajari keanekaragaman dan struktur komunitas semut pada tanaman lada. Melalui penelitian ini diharapkan dapat memberikan gambaran mengenai semut yang berasosiasi dengan tanaman lada untuk dapat digunakan sebagai data dasar dalam pemanfaatannya sebagai indikator kondisi habitat tanaman lada.

\section{BAHAN DAN METODE}

\section{Lokasi penelitian}

Lokasi penelitian terletak pada empat kabupaten di Provinsi Lampung yang merupakan sentra produksi tanaman lada (Gambar 1). Di setiap kabupaten dipilih dua lahan perkebunan lada di dalam satu desa (Tabel 1) dengan umur tanaman yang sama, yaitu 6 tahun untuk digunakan sebagai plot penelitian meliputi Desa Sekincau (Lampung Barat), Cahaya Negeri (Lampung Utara), Sukadana Baru (Lampung Timur) dan Negara Ratu (Lampung Selatan). Desa Sekincau merupakan daerah dataran tinggi, sedangkan ketiga desa yang lain masuk ke dalam kategori dataran rendah (Tabel 1). Di seluruh lokasi, tanaman lada ditanam dengan menggunakan tanaman hidup sebagai penegak, yaitu gamal (Gliricidia sepium) dan dadap (Erythrina subumbram).

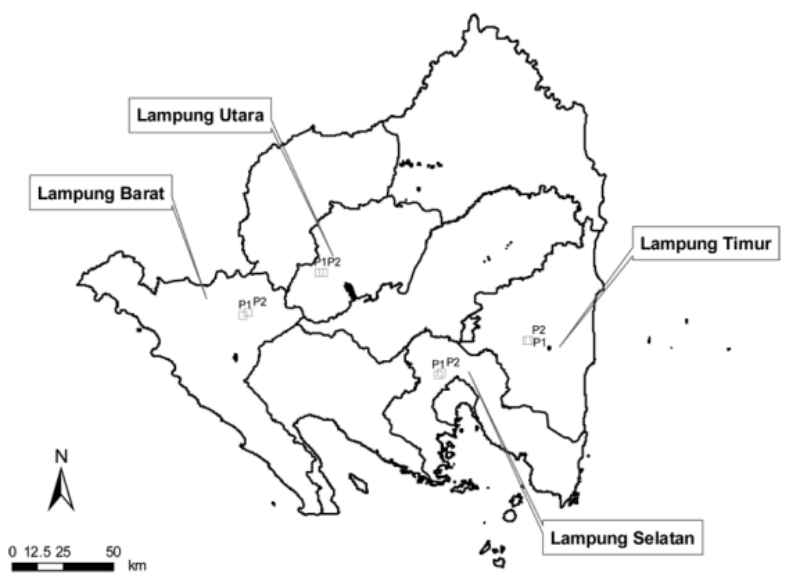

Gambar 1. Lokasi penelitian pada perkebunan lada di empat kabupaten di Provinsi Lampung. 
Tabel 1. Lokasi penelitian dan jumlah perangkap pitfall yang dipasang pada setiap plot di empat kabupaten di Provinsi Lampung

\begin{tabular}{|c|c|c|c|c|c|c|c|}
\hline Desa/Kabupaten & Plot & Latitude & Longitude & $\begin{array}{l}\text { Altitude } \\
\text { (m dpl) }\end{array}$ & $\begin{array}{l}\text { Curah } \\
\text { hujan } \\
(\mathrm{mm} / \mathrm{th})\end{array}$ & Budi daya & Kondisi habitat \\
\hline \multirow{2}{*}{$\begin{array}{l}\text { Sekincau/ } \\
\text { Lampung Barat }\end{array}$} & P1 & -5.054167 & 104.309233 & 1191 & \multirow[t]{2}{*}{1850} & \multirow{2}{*}{$\begin{array}{l}\text { Pengendalian } \\
\text { hama tanpa } \\
\text { pestisida }\end{array}$} & \multirow{2}{*}{$\begin{array}{l}\text { Lahan banyak } \\
\text { serasah } \\
\text { dan dekat } \\
\text { permukiman }\end{array}$} \\
\hline & $\mathrm{P} 2$ & -5.042367 & 104.330517 & 1191 & & & \\
\hline \multirow{2}{*}{$\begin{array}{l}\text { Negara Ratu/ } \\
\text { Lampung Selatan }\end{array}$} & P1 & -5.318167 & 105.172833 & 72 & \multirow[t]{2}{*}{1230} & \multirow{2}{*}{$\begin{array}{l}\text { Pengendalian } \\
\text { hama tanpa } \\
\text { pestisida }\end{array}$} & \multirow{2}{*}{$\begin{array}{l}\text { Lahan tanpa } \\
\text { gulma } \\
\text { dan dekat } \\
\text { permukiman }\end{array}$} \\
\hline & P2 & -5.310750 & 105.188350 & 72 & & & \\
\hline \multirow{2}{*}{$\begin{array}{l}\text { Sukadana Baru/ } \\
\text { Lampung Timur }\end{array}$} & P1 & -5.167600 & 105.575150 & 113 & \multirow[t]{2}{*}{2170} & \multirow{2}{*}{$\begin{array}{l}\text { Pengendalian } \\
\text { hama tanpa } \\
\text { pestisida }\end{array}$} & \multirow{2}{*}{$\begin{array}{l}\text { Lahan tanpa } \\
\text { gulma dan } \\
\text { jauh dari } \\
\text { permukiman }\end{array}$} \\
\hline & $\mathrm{P} 2$ & -5.167500 & 105.567817 & 113 & & & \\
\hline \multirow{2}{*}{$\begin{array}{l}\text { Cahaya Negeri/ } \\
\text { Lampung Utara }\end{array}$} & P1 & -4.865100 & 104.643567 & 170 & \multirow[t]{2}{*}{2160} & \multirow{2}{*}{$\begin{array}{l}\text { Pengendalian } \\
\text { hama tanpa } \\
\text { pestisida }\end{array}$} & \multirow[b]{2}{*}{$\begin{array}{l}\text { Lahan ditutupi } \\
\text { olehlegume } \\
\text { cover crop } \\
\text { (LCC) dan } \\
\text { jauh dari } \\
\text { permukiman }\end{array}$} \\
\hline & $\mathrm{P} 2$ & -4.866883 & 104.662783 & 170 & & & \\
\hline
\end{tabular}

\section{Pengambilan contoh serangga}

Metode yang digunakan untuk melakukan pengambilan contoh serangga adalah dengan menggunakan perangkap pitfall (perangkap jebak). Perangkap ini merupakan perangkap yang umum digunakan untuk mengkoleksi serangga permukaan tanah khususnya semut (Bestelmeyer et al. 2000). Pengambilan contoh serangga dilakukan di bulan Maret 2012, pada saat tanaman lada dalam kondisi awal berbuah yang merupakan salah satu fase yang sangat diperhatikan petani dalam mengendalikan hama. Kondisi permukaan tanah tidak banyak ditutupi oleh gulma karena sering dilakukan penyiangan. Pada seluruh lokasi tidak dilakukan penyemprotan pestisida maupun pemupukan. Pada setiap plot dipilih 10 pohon lada untuk dilakukan pemasangan perangkap pitfall. Perangkap dipasang selama tiga hari untuk kemudian serangga yang terperangkap diawetkan dengan alkohol 70\% dan dibawa ke laboratorium untuk proses sortasi dan identifikasi.

\section{Identifikasi}

Keseluruhan semut yang diperoleh diidentifikasi hingga genus (Bolton 1994) untuk kemudian pembedaan spesies (morfospesies) dilakukan berdasarkan perbedaan karakter morfologinya (Lattke 2000). Apabila memungkinkan, beberapa genus dilakukan identifikasi hingga tingkat spesies. Spesies kemudian diidentifikasi apakah termasuk semut tramp (semut yang berasosiasi dengan keberadaan manusia) atau semut invasif menurut McGlynn (1999) .

\section{Analisis data}

Kurva akumulasi spesies (Colwell \& Coddington 1994) digunakan untuk mendapatkan gambaran mengenai keanekaragaman semut pada setiap lokasi, sedangkan Chao estimator (Colwell \& Coddington 1994) digunakan untuk mengetahui keefektifan metode yang digunakan. Kemiripan komposisi spesies dilakukan analisis dengan menggunakan analisis multi dimensional scaling (MDS) berdasarkan indeks kemiripan Bray-Curtis (Legendre \& Legendre 1998). Untuk mengetahui perbedaan komposisi dilakukan analisis lanjut dengan menggunakan analisis kemiripan (ANOSIM). Seluruh analisis dilakukan menggunakan perangkap lunak $\mathrm{R}$ statistik ( $\mathrm{R}$ Development Core Team 2012) dengan package vegan (Oksanen et al. 2013). 
HASIL

Keanekaragaman semut pada habitat tanaman lada

Berdasarkan pemasangan perangkap pitfall yang dilakukan pada empat kabupaten di Lampung, sebanyak 28 spesies dari 5 subfamili semut teridentifikasi berasosiasi dengan tanaman lada (Tabel 2). Kabupaten Lampung Selatan yang memiliki ketinggian paling rendah dibandingkan dengan tiga kabupaten yang lain, memiliki keanekaragaman semut paling tinggi (Gambar 2, Tabel 2).Walaupun demikian, hasil estimasi dengan menggunakan Chao menunjukkan bahwa Lampung Barat yang merupakan dataran tinggi dan dengan sistem pertanian tidak intensif (Tabel

Tabel 2. Keanekaragaman semut pada empat lokasi penelitian, dengan masing-masing dua plot (P1 dan P2) untuk setiap lokasi

\begin{tabular}{|c|c|c|c|c|c|c|c|c|c|}
\hline \multirow{2}{*}{ No } & \multirow{2}{*}{ Spesies } & \multicolumn{2}{|c|}{ Lampung Barat } & \multicolumn{2}{|c|}{ Lampung Selatan } & \multicolumn{2}{|c|}{ Lampung Timur } & \multicolumn{2}{|c|}{ Lampung Utara } \\
\hline & & P1 & $\mathrm{P} 2$ & P1 & $\mathrm{P} 2$ & P1 & $\mathrm{P} 2$ & $\mathrm{P} 1$ & $\mathrm{P} 2$ \\
\hline \multicolumn{10}{|c|}{ Dolichoderinae } \\
\hline 1. & Dolichoderus sp.01 & 1 & & & & & 1 & & \\
\hline 2. & Tapinoma sp.01 & & & 2 & 3 & & & 7 & 2 \\
\hline 3. & Technomyrmex sp.01 & 1 & & & 2 & & & & \\
\hline \multicolumn{10}{|c|}{ Formicinae } \\
\hline 4. & Acropyga sp.01 & 1 & & & 2 & & & & \\
\hline 5. & Anoplolepis gracilipes $*$ & & & 1 & 6 & 2 & & 10 & 27 \\
\hline 6. & Camponotus sp.01 & 4 & & 5 & 4 & & 2 & 6 & 5 \\
\hline 7. & Nylanderia sp.01 & 2 & & 5 & 3 & 1 & & 1 & \\
\hline 8. & Nylanderia sp.02 & 3 & 3 & 1 & 3 & 1 & 1 & 3 & 1 \\
\hline \multicolumn{10}{|c|}{ Myrmicinae } \\
\hline 9. & Aphaenogaster sp.01 & 41 & 46 & & 1 & 9 & & & \\
\hline 10. & Crematogaster sp.01 & 2 & & 4 & 1 & 1 & & & 7 \\
\hline 11. & Crematogaster sp.02 & & & & & & & 1 & 20 \\
\hline 12. & Crematogaster sp.03 & & & & & & & & 3 \\
\hline 13. & Mayriella sp.01 & & & 1 & & & & 1 & \\
\hline 14. & Mayriella sp.02 & & & & & & & 38 & 3 \\
\hline 15. & Monomorium sp.01 & & & 14 & 3 & 42 & 32 & 6 & \\
\hline 16. & Monomorium sp.02 & & & & 1 & & 5 & 6 & \\
\hline 17. & Monomorium sp.03 & 1 & & 3 & 6 & 1 & 1 & & \\
\hline 18. & Pheidole sp.01 & 8 & 211 & 59 & 45 & 152 & 2 & 1 & \\
\hline 19. & Pheidole sp.02 & & & 5 & 1 & & & & \\
\hline 20. & Pheidole sp.03 & 41 & & & & & & & \\
\hline 21. & Pheidole sp.04 & 13 & & & & & & & \\
\hline 22. & Rhoptromyrmex sp.01 & 2 & 1 & 1 & 3 & 4 & & & \\
\hline 23. & Solenopsis geminata* & & & 111 & 54 & & & & \\
\hline \multicolumn{10}{|c|}{ Ponerinae } \\
\hline 24. & Hypoponera sp.01 & 2 & & & & 4 & 5 & & \\
\hline 25. & Leptogenys sp.01 & 1 & 2 & & & & & & \\
\hline 26. & Odontoponera sp.01 & 19 & 40 & 23 & 13 & 11 & 4 & 17 & 6 \\
\hline 27. & Ponera sp.01 & 1 & & & & & & & \\
\hline \multicolumn{10}{|c|}{ Pseudomyrmecinae } \\
\hline 28. & Tetraponera sp.01 & & & & 1 & & & 1 & \\
\hline
\end{tabular}


1) memiliki keanekaragaman semut paling tinggi karena baru sekitar $52 \%$ spesies semut berhasil dikoleksi di lokasi tersebut dibandingkan dengan Lampung Selatan yang telah mencapai 68\% spesies semut terkoleksi (Gambar 2).

\section{Perbedaan komposisi semut antar lahan tanaman lada}

Hasil analisis MDS menunjukkan bahwa komposisi spesies semut berbeda untuk setiap lahannya (Gambar 3). Keempat kabupaten di Lampung secara signifikan tidak memiliki kemiripan spesies semut berdasarkan ANOSIM (R $=0,563 ; \mathrm{P}=0,024)$. Spesies yang ditemukan di seluruh lokasi, yaitu Nylanderia sp.02, Pheidole sp.01 dan Odontoponera sp.01. Spesies yang lain hanya ditemukan pada lokasi tertentu, seperti spesies semut tramp dan invasif, yaitu Anoplolepis gracilipes dan Solenopsis geminata hanya ditemukan pada daerah dataran rendah (Tabel 2).

\section{PEMBAHASAN}

Keanekaragaman semut pada perkebunan lada khususnya semut-semut permukaan tanah lebih dipengaruhi oleh kondisi habitat yang ada di dalamnya. Lampung Barat dan Lampung Selatan memiliki keanekaragaman yang tinggi mengingat lokasi kebun yang relatif dekat dengan lokasi permukinan penduduk. Sistem budi daya ternyata tidak memengaruhi keanekaragaman semut pada perkebunan lada. Kondisi habitat yang berdekatan permukiman cenderung memfasilitasi keberadaan semut-semut tramp atau semut yang biasa berasosiasi dengan manusia (McGlynn 1999). Berdasarkan metode yang digunakan, keempat wilayah memiliki keanekaragaman dan komposisi spesies yang berbeda. Hal tersebut menunjukkan bahwa perbedaan kondisi lahan sangat memengaruhi keanekaragaman semut yang ada pada suatu daerah. Setiani et al. (2010) menemukan bahwa perbedaan kondisi habitat sekitar lahan persawahan memengaruhi keanekaragaman semut yang ada pada lahan persawahan

Sebagai sentra produksi lada, keempat kabupaten yang dijadikan sebagai lokasi penelitian memiliki perbedaan iklim, seperti curah hujan. Perbedaan curah hujan disinyalir memengaruhi

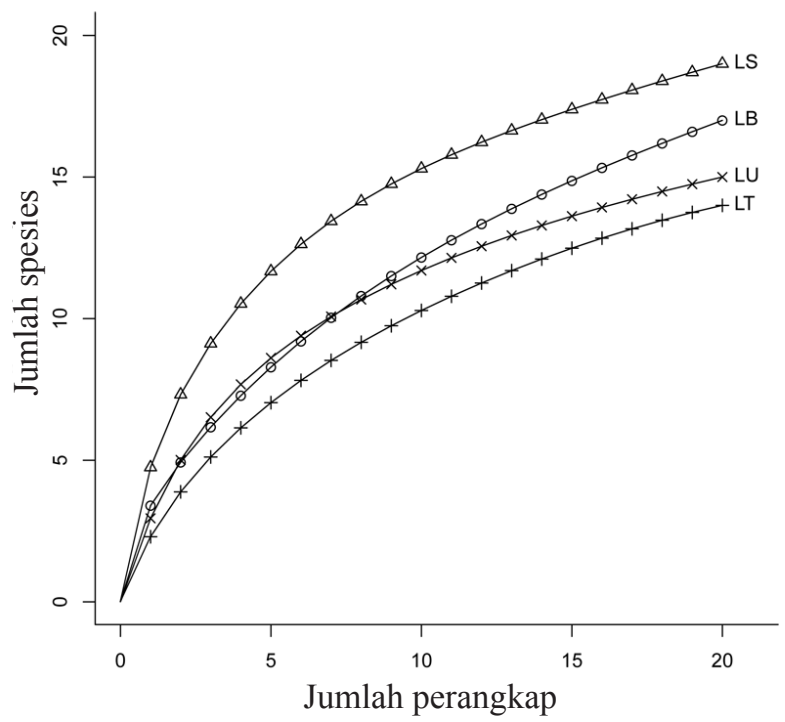

Gambar 2. Kurva akumulasi spesies semut yang ditemukan pada empat daerah penelitian. LS: Desa Negara Ratu, Lampung Selatan; LB: Desa Sekincau, Lampung Barat; LU: Desa Cahaya Negeri, Lampung Utara; LT: Desa Sukadana Baru, Lampung Timur. Proporsi spesies hasil observasi/estimasi Chao: $\mathrm{LB}=$ 17/33 (52\%); LS = 19/28 (68\%); LT = 14/17 (85\%); dan LU = 15/21 (71\%).

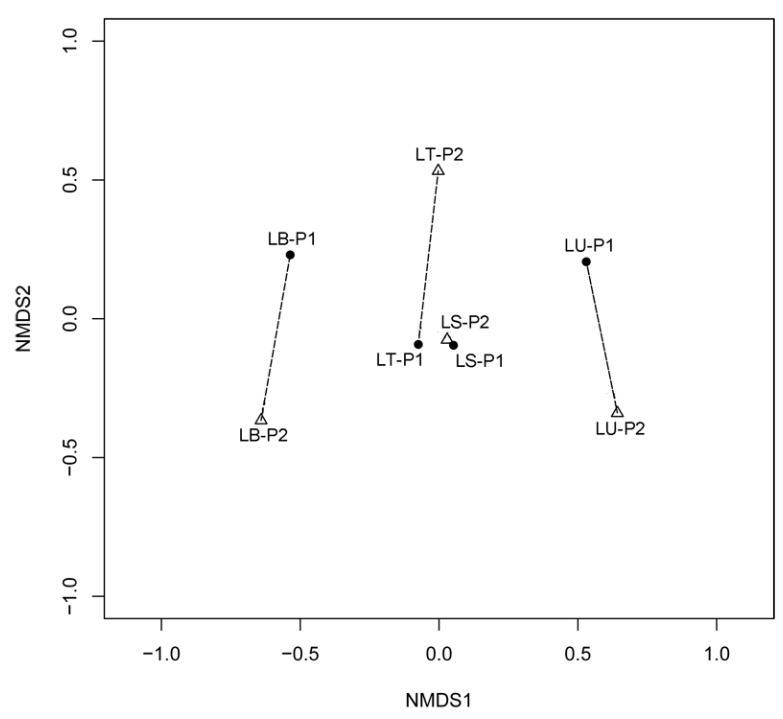

Gambar 3. Analisis MDS dari kemiripan spesies semut antar lokasi penelitian berdasarkan indeks kemiripan Braycurtis (stress $=0,013$ ). LB: Lampung Barat; LT: Lampung Timur; LS: Lampung Selatan; LU: Lampung Utara. P1: Plot 1; P2: Plot 2. 
perbedaan komunitas semut, seperti yang terjadi pada perkebunan kakao (Rizali et al. 2013). Curah hujan dalam hal ini memengaruhi ketersediaan iklim mikro dan sekaligus menyebabkan pembatasan niche pada spesies tertentu yang menjadikan perbedaan komposisi semut antar habitat yang berbeda (MacArthur \& Levins 1967; Andersen 2000).

Faktor iklim juga disinyalir memberikan pengaruh terhadap keberadaan spesies semut invasif. Walaupun demikian, keberadaan spesies semut invasif yang ada pada perkebunan lada berpotensi sebagai predator untuk pengendali hama (Way et al. 1998) disamping memiliki dampak negatif terhadap keberadaan semut yang lain (Holway et al. 2002). Semut invasif, seperti A. gracilipes dan $S$. geminata yang mampu beradaptasi dengan kondisi lingkungan ekstrim (Holway et al. 2002) menyebabkan semut ini lebih dapat bertahan dibandingkan dengan kelompok semut yang lain. Di sisi lain, hubungan mutualisme antara semut invasif dan hama khususnya dari kelompok Hemiptera menjadi permasalahan sendiri di dalam pemanfaatan semut dalam pengelolaan hama tanaman lada. Semut invasif dalam hal ini memanfaatkan sekresi gula yang dikeluarkan oleh hama, sedangkan hama mendapatkan perlindungan semut dari serangan predator lain.

\section{KESIMPULAN}

Keanekaragaman semut yang ditemukan di perkebunan lada di empat kabupaten di Lampung berjumlah 28 spesies, dua spesies diantaranya merupakan spesies semut invasif. Berdasarkan struktur komunitas semut, tidak terdapat kemiripan komposisi spesies antar keempat wilayah perkebunan lada. Perbedaan keanekaragaman semut antara lokasi lebih dipengaruhi oleh kondisi lingkungan di sekitar perkebunan lada.

\section{UCAPAN TERIMA KASIH}

Penulis mengucap terima kasih kepada Widilisanto, Sutomo, dan Rizki yang telah membantu dalam penelitian. Penelitian ini 70 dibiayai oleh Direktorat Pendidikan Tinggi (Dikti), Kementrian Pendidikan dan Kebudayaan, melalui program beasiswa BPPS.

\section{DAFTAR PUSTAKA}

Altieri MA. 1999. The ecological role of biodiversity in agroecosystems. Agriculture, Ecosystems \& Environment 74:19-31. doi: http://dx.doi. org/10.1016/S0167-8809(99)00028-6.

Andersen AN. 2000. Global ecology of rainforest ants: functional groups in relation to environmental stress and disturbance. In: Agosti D, Majer JD, Alonso LE, Schultz TR (Eds.), Ants: Standard Methods for Measuring and Monitoring Biodiversity. pp. 25-34. Washington: Smithsonian Institution Press.

Andersen AN, Hoffmann BD, Müller WJ, Griffiths AD. 2002. Using ants as bioindicators in land management: simplifying assessment of ant community responses. Journal of Applied Ecology 39:8-17. doi: http://dx.doi.org/10.1046/ j.1365-2664.2002.00704.x.

Bestelmeyer BT, Agosti D, Alonso LE, Brandão CRF, Brown WL Jr., Delabie JHC, Silvestre R. 2000. Field techniques for the study of grounddwelling ants: an overview, description, and evaluation. In: Agosti D, Majer JD, Alonso LE, Schultz TR (Eds.), Ants: Standard Methods for Measuring and Monitoring Biodiversity. pp. 122-144. Washington: Smithsonian Institution Press.

Bolton B. 1994. Identification Guide to the Ant Genera of the World. Cambridge: Harvard University Press.

Colwell RK, Coddington JA. 1994. Estimating terrestrial biodiversity through extrapolation. Philosophical Transactions of the Royal Society B: Biological Sciences 345:101-118. doi: http:// dx.doi.org/10.1098/rstb.1994.0091.

Hölldobler B, Wilson EO. 1990. The Ants. Cambridge: Harvard University Press. doi: http://dx.doi.org/10.1007/978-3-662-10306-7.

Holway DA, Lach L, Suarez AV, Tsutsui ND, Case TJ. 2002. The causes and consequences of ant invasions. Annual Review of Ecology and Systematics 33:181-233. doi: http://dx.doi. org/10.1146/annurev.ecolsys.33.010802.150444.

Lattke JE. 2000. Specimen processing: building and curating an ant collection. In: Agosti D, Majer JD, Alonso LE, Schultz TR (Eds.), Ants: Standard Methods for Measuring and Monitoring 
Biodiversity. pp. 155-171. Washington: Smithsonian Institution Press.

Legendre P, Legendre L. 1998. Numerical ecology 2nd English Edition. Dordrecht: Elsevier.

MacArthur R, Levins R. 1967. The limiting similarity, convergence, and divergence of coexisting species. American Naturalist 101:377-385. doi: http://dx.doi.org/10.1086/282505.

McGlynn TP. 1999. The worldwide transfer of ants: geographical distribution and ecological invasions. Journal of Biogeography 26:535548. doi: http://dx.doi.org/10.1046/j.13652699.1999.00310.x.

Oksanen J, Blanchet FG, Kindt R, Legendre P, Minchin PR, O'Hara RB, Simpson GL, Solymos P, Stevens MHH, Wagner H. 2013. Vegan: Community Ecology Package. R package version 2.0-6: Available at: http://CRAN.R-project.org/ package=vegan. [accessed Juli 2013].

R Development Core Team. 2012. R: A language and environment for statistical computing. Vienna: $\mathrm{R}$ Foundation for Statistical Computing.

Rizali A, Buchori D, Triwidodo H. 2002. Insect diversity at the forest margin-rice field interface: indicator for a healthy ecosystem. HAYATI Journal of Biosciences 9:41-48. doi: http:// dx.doi.org/10.3390/d5010026.

Rizali A, Clough Y, Buchori D, Tscharntke T. 2013. Dissimilarity of ant communities increases with precipitation, but not reduced land-use intensity, in Indonesian cacao agroforestry. Diversity 5:2638. doi: http://dx.doi.org/10.3390/d5010026.

Rizali A, Clough Y, Buchori D, Hosang MLA, Bos MM, Tscharntke T. 2012. Long-term change of ant community structure in cacao agroforestry landscapes in Indonesia. Insect Conservation and Diversity 6:328-338. doi: http://dx.doi. org/10.1111/j.1752-4598.2012.00219.x.

Rizali A, Lohman DJ, Buchori D, Prasetyo LB, Triwidodo H, Bos MM, Yamane S, Schulze CH. 2010. Ant communities on small tropical islands: effects of island size and isolation are obscured by habitat disturbance and 'tramp' ant species. Journal of Biogeography 37:229-236. doi: http:// dx.doi.org/10.1111/j.1365-2699.2009.02194.x.

Schowalter TD. 2011. Insect Ecology: An Ecosystem Approach, 3 edn. Oxford: Elsevier.

Setiani EA, Rizali A, Moerfiah, Sahari B, Buchori D. 2010. Ant diversity in rice field in urban landscape: investigation on the effect of habitat condition and age of rice plant. Jurnal Entomologi Indonesia 7:88-99.

Settle WH, Ariawan H, Astuti ET, Cahyana W, Hakim AL, Hindayana D, Lestari AS, Pajarningsih, Sartanto. 1996. Managing tropical rice pests through conservation of generalist natural enemies and alternative prey. Ecology 77:19751988. doi: http://dx.doi.org/10.2307/2265694.

Tylianakis JM, Tscharntke T, Lewis OT. 2007. Habitat modification alters the structure of tropical hostparasitoid food webs. Nature 445:202-205. doi: http://dx.doi.org/10.1038/nature05429.

Way MJ, Islam Z, Heong KL, Joshi RC. 1998. Ants in tropical irrigated rice: distribution and abundance, especially of Solenopsis geminata (Hymenoptera: Formicidae). Bulletin of Entomological Research 88:467-476. doi: http:// dx.doi.org/10.1017/S0007485300042218.

Wilson EO. 1990. Success and Dominance in Ecosystems: The Case of Social Insects. Olderdorf/Luhe: Ecology Institut. 